\title{
Article
}

\section{Transformational learning: Integrated Education for Integrated Care and Services}

Gurbutt, Dawne and Milne, Paul

Available at http://clok.uclan.ac.uk/26376/

Gurbutt, Dawne and Milne, Paul (2019) Transformational learning: Integrated Education for Integrated Care and Services. INTED2019 Proceedings . pp. 382389. ISSN 2340-1079

It is advisable to refer to the publisher's version if you intend to cite from the work. 10.21125/inted.2019

For more information about UCLan's research in this area go to http://www.uclan.ac.uk/researchgroups/ and search for < name of research Group>.

For information about Research generally at UCLan please go to http://www.uclan.ac.uk/research/

All outputs in CLoK are protected by Intellectual Property Rights law, including Copyright law. Copyright, IPR and Moral Rights for the works on this site are retained by the individual authors and/or other copyright owners. Terms and conditions for use of this material are defined in the policies page.

\section{CLoK}

Central Lancashire online Knowledge www.clok.uclan.ac.uk

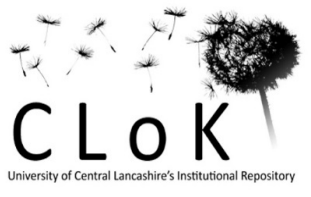




\title{
TRANSFORMATIONAL LEARNING: INTEGRATED EDUCATION FOR INTEGRATED CARE AND SERVICES
}

\author{
Gurbutt, Dawne ${ }^{1}$, Milne, Paul ${ }^{2}$ \\ 1 University of Central Lancashire, UK \\ ${ }^{2}$ University of Central Lancashire, UK
}

\begin{abstract}
The National Health Service in the UK is placing increased emphasis on Integrated Care and closer working relationships between services and professions. This provides both a challenge and an opportunity for universities preparing students for clinical roles as it represents a shift, supported by technology, away from traditional modes of learning and, ultimately, of practice. The creation of new medical school at the University of Central Lancashire UK facilitated an increased emphasis on Interprofessional education (IPE), driven in part by the requirements of the professional bodies. Utilising a strong activity theory pedagogy resulted in the development of a forum theatre approach to case studies using interactive learning elements and small group work across professions, the programme involved nine professional groups from four schools across the university. Sessions involved service users and actors as well as the student participants and staff from all courses. The data from evaluations from across the 7 session programme $(\mathrm{N}=1742)$ indicated that students appreciated the importance of IPE whilst some found it challenging. Issues identified as challenging included lack of confidence, IPE not being examinable resulting in some students devaluing the experience, and timetable issues. However, students gained insights into the roles and skills of others, viewed health services more holistically and agreed that IPE was a useful preparation for practice. Some students developed inter-cohort relationships which extended beyond the classroom into informal learning settings. The commitment of staff to integrated learning and collaborative practice was central to the transformative elements of learning experience, leading to discussion of values and a clear patient focus. Initially arising from the development of the medical curriculum, staff ownership of IPE has resulted in a wide level of engagement across the university incorporating interdisciplinary as well as inter-professional learning and involving a broader pedagogic approach. This has resulted in the development of digital approaches to support collaboration and the development of staff interdisciplinary groups and communities of practice across the institution.
\end{abstract}

Keywords: Innovation, Interprofessional Education, Collaboration, Technology

\section{INTRODUCTION}

In 2015, The General Medical Council of the UK (GMC) gave approval for the University of Central Lancashire (UCLAN), a post-1992 University, to deliver medical undergraduate education and create a new Medical School. The first intake accepted 36 International Medical students onto the MBBS programme, bringing together learners with experience of very different healthcare systems from across the globe and with limited existing understanding of the National Health Service (NHS). The 
approval of new medical schools in the UK has accompanied a policy shift in relation to the need to train and retain practitioners to work within the different regions of the UK. Since 2010 the UK population has grown by $4 \%$ (2.1 million) and the general population is ageing. This has led to increased demand for doctors and nurses (HEE, 2017) [1] Expansion of Medical Education is a continuing trend: 'in 2016 the Health Secretary announced a historic expansion of medical students by 1,500 places, approximately a $25 \%$ increase, moving the NHS closer to self-sufficiency in doctors.' (HEE, 2017) [1] The policy context also incorporated a move towards closer collaboration in providing care and meeting care needs, the 'integrated care' agenda. In 2016, 44 sustainability and transformation partnerships were created across England to achieve this aim : 'In an integrated care system, NHS organisations, in partnership with local councils and others, take collective responsibility for managing resources, delivering NHS standards, and improving the health of the population they serve' ( NHS, 2018) [2] The increasing emphasis on Integrated Care, renders the need to provide undergraduate with the opportunity to work together prior to qualification more of a priority in preparation for subsequent graduate roles.

The creation of new medical school provided an unparalleled opportunity to design a new and contemporary curriculum within the parameters established by the statutory professional body in, initially, the 'Tomorrows Doctors' document (1993) [3] and then the revised guidance: 'Outcomes for Graduates' document (2015) [4], but with the scope to shape curriculum based on the pedagogic values and clinical educational experiences of the core curriculum team. Gurbutt and Milne (2018) [5] described the imperative to involve service users in design, delivery and evaluation, responding to the issues which arose from the reports of the enquiry into failings in the Mid-Staffordshire hospital trust (Francis, 2013) [6] and the resultant emphasis on the importance of 'values' in health and social care programmes (NMC 2014, GMC 2015.) [7]. 'Integrated Care' approaches were developed as a way of developing practice raising the profile nationally of collaborative learning and teaching (NHS, 2014) [8] which in turn led to an emphasis on interprofessional education within the new curriculum, utilising the work of the Centre for Advancement of Interprofessional Education, (CAIPE) [9]. CAIPE describes meaningful learning as learning 'from, with and between' learners, but which ultimately is seen as impacting patient outcomes. Pedagogic perspectives arose from understanding that learners learn in structured learning events, but also in informal settings drawing on the work of Englestrom, et al 1995 [10]. The theoretical underpinning for the IPE programme was carefully constructed and the design remained true to the established principles. See Gurbutt and Milne (2018) [5] for insights into the theoretical framework.

The 2018 BEME review [11] of the contribution of theory to the delivery of interprofessional curricula reviews and evaluates the role of social and cognitive theories. Activity system theory (Culturo-Historic Activity Theory, CHAT) is discussed as being useful when considering 'Process' in the development of an IPE programme. The BEME review (2018) cites Daniels work using CHAT commenting that

"The workshops were designed to direct the attention of participants to the ways in which structural contradictions may be hidden within interagency practices and provide them with 
activity systems as tools to facilitate their resolution. Qualitative evaluations of these workshops match the theoretical perspectives of the work-shops themselves".[12]

The IPE programme was purposively developed around this theory and that it was likely that the resultant interactions between individual and group Activity systems would be complex and therefore some outcomes could not be predicted. Hence overall the programme primarily made use of CHAT and Complex Adaptive System Theory. The authors would agree with the BEME review that no-one theory is the "Gold Standard" when developing an IPE programme and that it is important to have an underpinning of theoretical perspectives in its evaluation.

However, it would be wrong to assert that such interventions take place solely within the context of Medical and Healthcare education and practice. The wider elements of educational policy also impact learning. These include, in the UK, the importance of the Teaching Excellence Framework [11] an innovation which measures teaching excellence in higher education using a range of published metrics and for which universities submit data and are subsequently listed as achieving Gold, Silver or Bronze for teaching quality. The National Student Survey (2018) [12] which enables students on HE undergraduate courses in their final year to provide feedback on student experience. There are also internal drivers within the University, such as the Learning and Teaching Strategy which places emphasis on a positive student experience and emphasising excellent pedagogy (UCLan, 2017) [13].

These drivers focus attention on the accessibility of learning for students, inclusivity and creativity within the curriculum. These considerations underpinned the decision to utilised flipped classroom resources to support IPE sessions and to record learning sessions using RELAY technology to enable students to revisit learning from sessions at a later date and to encourage students to share their learning using web-based applications. Addressing the creativity element, most sessions were based around a 'body systems' approach to learning using actors in a forum-theatre style presentation, delivering a pre-created script, facilitated by academic staff with a practitioner background and with interactive elements in the form of discussions and subsequent small breakout groups.

\section{CONTEXT AND METHODOLOGY}

This project was closely linked to curriculum development and as part of this ethical approval was sought and gained to evaluate and research the experiences of the Medical students and the cohorts working directly alongside them in the Interprofessional education series. Evaluations comprised feedback from 1994 learning episodes, this represented the number of students multiplied by the number of sessions (students completed evaluations for each session) across the programmes. These sessions included: case-based, systems focused studies which began in large forum-theatre sessions and later split down into 14 small groups; whole day events which began with a service user presentation and then interdisciplinary facilitated small groups. This paper is concerned primarily the evaluation of the first of these modes, which formed the majority of the total of 1994 learning episodes that were evaluated. For the purposed of this paper the focus is on the qualitative comments which 
students made on evaluation forms, rather than statistical data (which has been reported elsewhere) and comments from focus groups. Furthermore, the focus of this paper is the evaluations of participants across the core IPE MBBS events within one year, representing input from both years in phase one: 1742 evaluations in total. Extensive questionnaires were used in addition to student focus groups. Students were informed of the study and gave their informed consent to being part of the study. The purpose of the study was reiterated at each point where evaluation was sought, and students did not experience any disadvantage from non-participation. Although some contextual data was sought from students as to their programme of study, in other respects the data was anonymous. There were also sessions for staff evaluations, these took place both within disciplinary teams and amongst the wider group of facilitators.

\section{OPPORTUNITIES TO LEARN}

Students were given multiple opportunities to engage with and learn from IPE material. For first years this included the use of four flipped classroom elements, three delivered prior to the sessions and focused on policy, context and roles and responsibilities and one based around reflection completed after the face-to-face session. The main part of the IPE session was recorded and could be re-viewed later, this was important for international students who might not be familiar with particular aspects of language. For the forum theatre and service user led IPE sessions the main session took place in large learning spaces such as lecture theatres, with students sitting in interprofessional groups with a facilitator who had pre-devised prompt questions to promote discussion in breakout opportunities within the session. There was then also small group- work taking place immediately after the main session and facilitated by tutors. For second years the sessions were comprised of a service user presentation or presentations followed by interdisciplinary group work in small groups with a facilitator on a problem-based study. Students worked in groups to prepare and then present potential solutions and resources.

\section{EVALUATION}

The majority of students found the sessions helpful in building confidence, learning about service users and developing insights into other roles and professional issues, this was reflected in the responses to questions on the questionnaire. The findings which we draw upon here, are taken from the 'free text' part of the questionnaires and use exemplar statements to illustrate recurrent themes. It must however be emphasised that not all students commented in the free form text boxes, but that these comments provide additional insights into student perceptions of learning.

The written comments from the evaluations can be considered under a number of themes. These include student learning, staff learning and institutional learning as well as impact of the sessions and approach. 


\subsection{Student learning}

Comments relating to student learning could be organised into themes, these included: learning about staff, learning about each other, learning about themselves and understanding their own learning

\subsubsection{Learning about staff}

One of the key findings for students was learning about staff. Mostly this was very positive learning and illustrated the importance students place on staff attitudes and behaviour. Students commented on the importance of seeing their tutors as 'practitioners' as well as subject experts.

'when they are giving examples from practice , I think 'you have really done this, you know what you are talking about.

'I like listening to their examples, you sort of see a different side of them'

Paul talks about when he was a GP - and I can see him doing it, I have respect for that .

They also commented on the values they observed in staff relating to collaborative working.

' when I see them making this work, I realise that they are not just talking about working together, but they are working together themselves, it is interesting to watch how they do it.'

'it is really good to see how the staff are with the service users, their attitude to them is sort of what unites them, they might be very different, but they all show how important the patient is...'

' it sort of came to me - that they reflect - it isn't just theory - they reflect on their own practice why is that surprising to me? I am not sure, I didn't think about it I suppose.'

'some staff are more open than others, they model the sort of practitioner I would like to be' 'you can tell that they love talking about practice - it comes alive.'

Not all comments were positive though 'one tutor tells us that she didn't have to do this when she was a student, I can tell she thinks it is a waste of time - and I agree - we will do this eventually in practice, why do we need to do it now?'

'if they don't value it - why should we?'

I'm not sure we need to learn about other people, isn't it more important that they learn from us? I am not sure what they can teach me.'

These statements demonstrate that teachers 'teach' even when they might not see themselves as doing so and that students are learning about attitudes and values alongside course content. A key indicator of the power of the 'hidden curriculum'

\subsubsection{Learning about each other}

Learning included about others' roles and skills:

'it has been good to find out in more detail what other people do ' 
'I have really been able to see the skills other people have and why we need to work in teams' 'we have really got on, some of us have met for a coffee outside of lessons, it has been good.' 'we got the opportunity to be involved in the health thing (Mela) and that was a great experience - a bit scary, but great'

'I quite like finding out what other people do and what makes them tick...'

'I think it will be nice on placement to see friendly faces in other places.'

'I don't think I like students from (group $x$ ) they don't have the same values as us.'

This final type of statement (of which there were a few) shows how exposure to others in IPE sessions could potentially reify negative attitudes and that students need places to explore these views and maybe the opportunity to challenge the values of others.

\subsubsection{Learning about themselves}

Students learning about themselves included challenges over time and volume of learning:

'I have struggled a bit with this, and I have asked myself why?'

'I would rather do other things, this takes up so much time and we don't even have an exam in it. I am sure it could be done differently.'

'I really like being with the service users, it is what I came for'

'sometimes there seems so much to learn it seems a bit scary'

I'm quite shy in this and I need to be more able to speak out - I can see that.'

'I am sometimes surprised at what I know.'

Students reported on their engagement and willingness to devote time to such learning:

I know what I like and what I enjoy and at times this all feels a bit slow for me'

'why do we spend so much time on things that don't have an exam.'

'I often don't read the flipped classrooms, I guess I would get more out of it if I did.;

'I prefer to work alone - I find explaining things to others quite challenging.'

\section{STAFF LEARNING}

\subsubsection{Learning about students}

Staff reported on their reflections about some students' approach to IPE:

'I was so surprised that they wanted an exam on this - I thought they would be relieved to not have to be tested on everything.' 
'they are so reluctant to break out of their own groups and yet they are going to work with strangers and the general public - why is that so hard for them to understand?'

'you can see some of the issues with identity in the room, either under or over confidence - makes you think more carefully about how you address it.'

'they already see themselves in a particular role, don't they? We are already needing to convince some of them to change.'

I was surprised that some of them find it so difficult to talk to service users- this is after all what they have chosen to do.'

\subsubsection{Learning about themselves}

Staff also derived benefit from the social aspect echoing practice experience:

'I enjoyed meeting other staff, it felt a bit like being back in practice.'

'I really value this, but it is so, so hard to fit it in, we need time to do it.'

'it reminded me of why I chose this, took me right back to practice'

'I enjoyed the group work, not teaching so much as sharing, although I know it is teaching, but the pressure is off to relate to assignments.'

'I have got to know colleagues I would never have met otherwise.'

\section{INSTITUTIONAL LEARNING}

Technology enabled learning and embedded resources were valued. This was balanced with the logistical work needed make the learning happen.

\subsubsection{Technology}

'the technology is great isn't it - I have been pushed to use it more with my own students.'

'the technology has helped us to collaborate - I don't think it would have happened without this (the surface pro) '

'I think the flipped classroom works well, but you do need time to create it - we just don't have time

\subsubsection{Resources}

'there are resources for this, without them it wouldn't get anywhere.'

'we need more resources to do this, it is good, but it is really time consuming.'

'you need designated people to make this work'

\subsubsection{Administration}

'Time tabling - aaarghh' 
'the students have no idea how much work we put into this' 'you need to begin really early and then keep at it, otherwise it will just not happen.' 'the group meetings work well, I find out all sorts of other things

\section{STUDENT EXPERIENCE}

It was clear that student experience was not consistent across the groups 'where you have a tutor, they know what they are doing and can run a session. Some of the other facilitators find it harder to keep it going, you know control a room effectively and get people to contribute.' We had used medical demonstrators to facilitate and some were more experienced than others

'you need staff who can sort out the students who aren't engaging. And we need to be treated equally, medical students have to attend, some of the others disappear at breaks.'

One interesting set of comments was from students from a non- health course who found themselves in the wrong session but stayed for the duration of the event

'this session was on Mental Health, it is probably the most useful session I have attended at university. I think everyone should have to do it.'

'I was absolutely fascinated, it made me see people who work in healthcare in a totally different way, the people I was with, well they sort of cared for me when they found out I was in the wrong place - I can't explain it, but somehow I feel I should ....'

\section{IMPACTS}

One of the key impacts for the first two years of the programme was that the very small minority of medical students who didn't like IPE were able to disproportionately influence the programme by arguing that they needed more time for revision and that the sessions were not as useful to them as disciplinary sessions. This coupled with a substantial increase in medical student numbers and the movement of some key staff out of the medical school resulted in the IPE being scaled back within the medicine. Understanding of IPE amongst medical tutors was also problematic in that some considered that learning from another health professional equated to IPE and therefore was easier to organise than sessions where students are enabled to learn from each other. The result was that IPE was moved to the latter portion of the programme rather than occurring at the beginning. Impacts outside of the medical school were somewhat more positive. The IPE amongst other health professionals has continued to grow and has now also incorporated interdisciplinary learning with Law, Criminal Justice, Art, Fashion, and Architecture in addition to other subjects. There is now a cross disciplinary university group working on innovative and collaborative projects around learning and teaching. Writing groups have been established to work collectively on scholarly outputs around collaboration, with a successful track record of publications and conference papers. A successful 'Cultivating Collaboration 'conference shared good practice in IDE from across the university and the 
university was well represented at international IPE conferences in 2018. The number of staff engaged in IPE has continued to grow and collaborations exist across the region and beyond. Healthcare and arts students have been invited to run exhibitions and events for local Hospital trusts which have been well received and students are actively involved in the Health Melas which take place in the area. Some learning and teaching has been maintained with the medical school, but this has been organised from within the Nursing school.

More recently innovations have again begun to be developed with the medical school and learning from the first iterations and from the successful IPE elsewhere will shape provision. IPE is often led by enthusiasts and individual movement of key staff can have a significant impact on innovation as IPE requires not only a champion, but consistent effort if it is to succeed.

On reflection, it was interesting that some students reflected the 'gaming nature' of their learning with the thoughts that 'it was only worth doing if there was an exam' (paraphrased). Methods of assessment were only considered in terms of attendance but other workers in this field have used 'Team Observed Structured Clinical Encounters' (TOSCE).(Hall et al 2013) cited in BEME review 2018 (16) . In terms of formative assessment this has some attraction and provide reification for students. There is a move towards involving student as partners in IPE to proactively inform design of sessions and the way in which IPE is framed and evaluated.

\section{CONCLUSIONS}

IPE is a worthwhile activity which currently fits well with Health, Education and Policy drivers. It has benefits for staff and students and institutions can learn much from it which can usefully enhance the student experience. There is no doubt that employers value the specific skills which emerge from working collaboratively and in preparing graduates for an interconnected world of wicked problems the skills of communication, prioritisation, professionalization, teamwork, decision making, and time management are of crucial importance. A strong underpinning pedagogy, commitment to a positive experience, resilience to overcome barriers - both structural and individual are necessary to a successful IPE endeavour. But the insights, rewards and value added to curriculum and community are worth the commitment.

\section{ACKNOWLEDGEMENTS}

Our thanks to the staff, students and service users who participated in the sessions.

\section{REFERENCES}

[1] HEE Health Education England (2017) 'Facing the Facts - Shaping the Future. A draft Health and Social Care Workforce strategy for England to 2027

https://www.hee.nhs.uk/sites/default/files/documents/Facing\%20the\%20Facts\%2C\%20Shaping\% 20the \%20Future\%20\%E2\%80\%93\%20a\%20draft\%20health\%20and\%20care\%20workforce\%20st rategy\%20for\%20England\%20to\%202027.pdf (accessed, Nov 2018) 
[2] NHS (2018) Integrated Healthcare systems.

https://www.england.nhs.uk/integratedcare/integrated-care-systems/ (accessed Nov 2018)

[3] GMC, Tomorrow's Doctors - Outcomes and Standards for Undergraduate Medical Education'. 2009. Accessed 1411 2018. Retrieved from: https://www.gmcuk.org/Tomorrow_s_Doctors_1214.pdf_48905759.pdf.

[4] GMC, Outcomes for Graduates, 2015. Accessed 1411 2018. Retrieved from: https://www.gmcuk.org/Outcomes_for_graduates_Jul_15_1216.pdf_61408029.pdf.

[5] Gurbutt, D.J and Milne, P. (2018) 'The Path to Transformation: Navigating the barriers to forming transient and transitional Learning Groups in Interprofessional Education.' INTED2018, Valencia, Spain. Published Proceedings.

[6] R. Francis, Report of the Mid-Staffordshire NHS Foundation Trust Public Inquiry, 2013. London: Stationary Office. Retrieved from: http://www.midstaffspublicinquiry.com/report. Accessed 1411 2018.

[7] NMC, Standards for Competence for Registered Nurses, 2014. Accessed 1411 2018, Retrieved from: https://www.nmc.org.uk/standards/additional-standards/standards-for-competence-forregistered-nurses/

[8] NHS, Five Year Forward View, 2014 Accessed 1411 2018. Retrieved from: https://www.england.nhs.uk/wp-content/uploads/2014/10/5yfv-web.pdf

[9] CAIPE, Centre for Advancement of Interprofessional Education. www.caipe.org.uk accessed 5.5.2018

[10] Y. Engeström, R. Engeström, M. Karkkainen, Polycontextuality and Boundary Crossing in Expert Cognition: Learning and Problem Solving in Complex Work Activities. Learning and Instruction, Vol.5, pp. 319-336. 1995.

[11] Hean, S., Anderson, E., Green, C., O’Halloran, C., Pitt, R., Morris, D., John, C., and Temple, J. (2018) 'A systematic review of the contribution of theory to the development and delivery of effective interprofessional curricula in health professional education. Medical Teacher, 40:6 542558 doi: 10.1080/0123159x2018.1432851

[12] Daniels, H., Leadbetter, J., Warmington, P., Edwards, A., Martin, D. Popova, A., Apostolov, A., Middleton, D., Brown,S. ( 2007) Learning in and for multiagency working. Oxford Rev Educ. $33: 521$

[13] Dept. of Education, Teaching Excellence Framework, 2017, Accessed 1610 2018, Retrieved from: https://www.gov.uk/government/news/universities-rated-in-teaching-excellence-framework London: GovUK

[14] HEFCE, National Student Survey, 2018, Accessed 1610 2018. Retrieved from: http://www.hefce.ac.uk/lt/nss/

[15] University of Central Lancashire, Learning and Teaching Strategy: Student Access, Experience and Success. Preston: UCLan, 2017.

[16 ] Hall P, Weaver L, Grassau PA. 2013. Theories, relationships and inter-professionalism: learning to weave. J Interprof Care. 27:73-80. 